\title{
A consciência fonológica no processo de alfabetização em pesquisas recentes
}

\section{Phonological awareness in the literacy process in recent research}

https://doi.org/10.34112/2317-0972a2019v37n76p27-40

Amanda dos Reis HermanN ${ }^{1}$

Heloisa Chalmers Sisla ${ }^{2}$

RESUMO: Este artigo visa identificar a presença da consciência fonológica e as formas como se manifesta o trabalho com ela em estudos recentes, por meio de uma pesquisa bibliográfica. Os artigos analisados foram reunidos em três grupos: pesquisas empíricas que reconhecem a importância da consciência fonológica, pesquisas documentais e bibliográficas e pesquisas empíricas que criticam o trabalho com a consciência fonológica. Ficou evidenciado que há práticas pedagógicas voltadas para o desenvolvimento da consciência fonológica pelas alfabetizadoras, mas que muitas vezes não aparecem com essa terminologia, sendo pouco explicitadas ou limitadas. Um dos dados mais preocupantes é o do grupo de trabalhos que rejeitam a consciência fonológica como necessária para a alfabetização. A alfabetização requer práticas contextualizadas, que abranjam as várias facetas do processo. PALAVRAS-CHAVE: Alfabetização; consciência fonológica; prática pedagógica.

ABSTRACT: This article aims to identify the presence and the ways in which the work with the development of phonological awareness in research reports. It is a bibliographical research. The articles analyzed were grouped into three: empirical researches that recognize the importance of phonological awareness; documentary and bibliographical research; and empirical

1. Universidade Federal de São Carlos, São Carlos, SP, Brasil.

2. Universidade Federal de São Carlos, São Carlos, SP, Brasil. 
researches that criticize pedagogical practices with phonological awareness. It was evidenced that there is the use of phonological awareness. One of the most worrisome data refers to the group of works that reject phonological awareness as necessary for learning how to read and write. The literacy process requires contextualized practices involving different facets.

KEYWORDS: Literacy; phonological awareness; pedagogical practice.

Compreender melhor o processo de aquisição da leitura e da escrita continua sendo um desafio. O tema está em pauta hoje frente à polêmica colocada pelo Secretário de Alfabetização do Ministério da Educação, que defende a adoção dos métodos fônicos e a necessidade de apresentar letras e sons para as crianças antes de atividades com textos (SCHREIBER, 2019), posicionamento contestado por Magda Soares (SEMIS, 2019) e por pesquisadores na área.

Neste trabalho será discutido um dos aspectos envolvidos no processo de alfabetização: a consciência fonológica. Para compreender suas contribuições, este artigo tem por objetivo identificar a presença da consciência fonológica e as formas como se manifesta o trabalho com ela em relatos de pesquisas das práticas pedagógicas.

Soares (2017) detalha as diferentes facetas envolvidas na alfabetização e apresenta as pesquisas recentes sobre elas, a partir da problematização da questão dos métodos, que, segundo ela, não são capazes por si mesmos de alfabetizar. Cada método privilegia apenas uma faceta da alfabetização, mas este processo envolve várias facetas, pois "um só componente - faceta - do processo de aprendizagem da língua escrita não resulta no produto: a criança alfabetizada e inserida no mundo da cultura escrita, a criança letrada” (p. 33). A autora defende que são três as principais facetas envolvidas no processo: linguística, interativa e sociocultural. A faceta linguística, equivalente à alfabetização, é a "aprendizagem do sistema alfabético-ortográfico de escrita” (p.36), responsável pela apropriação das relações entre fonemas e grafemas. Avançando em relação a suas concepções anteriores do sistema de escrita (SOARES, 1985; 2004), a mesma autora concebe o sistema alfabético tanto como representacional quanto notacional. É representacional porque representa os sons da fala e se materializa em um sistema notacional, constituído por um conjunto de notações, arbitrárias e convencionais, que representam os sons da fala.

As outras duas facetas compõem o processo que a autora até então denominara de letramento (SOARES, 1985; 2004), agora subdividido em facetas interativa e sociocultural, voltadas respectivamente para as habilidades de compreensão e produção de textos e para as ações de inserção em eventos de escrita. Ela mantém 
seu posicionamento de produções anteriores, de que todas as facetas deste processo entram em jogo na aquisição da leitura e da escrita e é preciso compreender e trabalhar cada uma, assim como as relações entre elas. A autora destaca a faceta linguística por considerá-la o alicerce das outras duas e por julgar necessário reinventar a alfabetização, que estaria secundarizada nas proposições teóricas e práticas (SOARES, 2004). Defende ainda que as facetas do letramento estão ancoradas na alfabetização, pois "dependem fundamentalmente do reconhecimento (na leitura) e da produção (na escrita) corretos e fluentes de palavras" (p.36).

Sob essa ótica, entende-se que a criança precisa compreender que a escrita representa os sons da fala. Ela terá que entender também que a habilidade que tem ao falar será expandida em novas habilidades de escrever e ler, e mais, que a língua se decompõe em unidades menores. Ao dominar esse processo, a criança estará avançando no domínio da consciência fonológica, "essa capacidade de focalizar os sons das palavras, dissociando-as de seu significado e de segmentar as palavras nos sons que as constituem" (SOARES, 2017, p. 166). Dentre as facetas linguísticas, a consciência fonológica é a que apresenta impacto mais expressivo no início da aquisição da escrita. ${ }^{3}$

Buscando entender melhor o processo de desenvolvimento da consciência fonológica, Soares (2017) indica níveis deste desenvolvimento, iniciando com a aprendizagem de rimas e aliterações (semelhanças entre os sons iniciais de palavras), passando depois à consciência das sílabas e posteriormente se concentrando nos fonemas, sendo que a percepção e aprendizagem destes é mencionada na literatura com terminologia própria, a consciência fonêmica. Reiterando tais especificidades, Fayol (2014, p. 51) aponta a existência de diversas segmentações - orações, palavras, sílabas, fonemas -, que poderiam constituir unidades capazes de suportar as associações entre as modalidades oral e escrita. Ele acrescenta que o processo de alfabetização que se utiliza da consciência fonológica, independentemente da metodologia utilizada, influencia a aquisição da leitura e escrita de maneira positiva.

A percepção e comparação com rimas e aliterações impacta o início da alfabetização: "rimas e aliterações representam, pois, um nível de sensibilidade fonológica que, se desenvolvido, pode trazer efeitos significativos para o processo de alfabetização: levam a criança a dirigir a atenção para a cadeia sonora das palavras” (SOARES, 2017, p. 184).

3. Soares (2017) indica diferentes facetas ao analisar a faceta linguística, as quais, entretanto, não serão objeto de análise neste trabalho, posto que o recorte aqui escolhido é o da consciência fonológica, pelo impacto que apresenta na fase inicial da alfabetização. 
A pesquisa foi desenvolvida por meio de análise bibliográfica. Foi realizada uma busca por artigos científicos nas bases de dados da ANPED (Associação Nacional de Pós-Graduação e Pesquisa em Educação), COLE (Congresso de Leitura) e SciELO (Scientific Electronic Library Online), de 2005 a 2017, utilizando os descritores alfabetização e letramento; alfabetização; consciência fonológica; e consciência fonológica na alfabetização. Em consonância com os referenciais teóricos anteriormente apresentados, foram excluídos os trabalhos voltados para análise de práticas com métodos fônicos, por, assim como outros métodos de base sintética, privilegiarem a alfabetização em detrimento do letramento. Nosso interesse se voltou para analisar o tratamento da consciência fonológica em estudos e práticas que adotassem perspectivas que incluíssem o letramento no processo. Tal opção se deu por considerarmos que muitas das pesquisas que não adotam a perspectiva fônica vêm sendo criticadas por não incluírem, ou incluírem de forma limitada, os aspectos linguísticos e em particular os relativos à consciência fonológica (SOARES, 2017). Para a inclusão neste artigo consideramos, portanto, os estudos cujos suportes teóricos eram constituídos por autores e autoras que optaram por perspectivas teórico-metodológicas diversas daquelas que defendem a adoção dos métodos fônicos de alfabetização, opção amparada na desconstrução que Mortatti (2009) empreende sobre os métodos fônicos.

Os trabalhos analisados, num total de treze, envolveram, mais ou menos explicitamente, práticas de professoras ${ }^{4}$ alfabetizadoras e fizeram menção à consciência fonológica. Quanto à perspectiva teórica, os estudos apoiavam-se em abordagens enunciativas, psicolinguísticas, sociolinguísticas e dos Novos Estudos do Letramento. Houve ainda trabalhos cuja fundamentação se encontrava nas áreas de formação de professores, da fabricação do cotidiano escolar, dos Estudos Culturais e da Transposição didática. Os artigos foram reunidos em três grupos, a saber: $1^{\circ}$ ) pesquisas empíricas sobre práticas nas quais a consciência fonológica era considerada importante para $o$ processo de alfabetização; $2^{\circ}$ ) pesquisas documentais e bibliográficas que se referiam à consciência fonológica na alfabetização, relativas a programas ou estudos que impactam nas práticas pedagógicas; e finalmente, $3^{\circ}$ ) os estudos empíricos sobre práticas com manifestações críticas à necessidade de um trabalho com consciência fonológica. Observou-se a prevalência de estudos de base empírica, num total de nove trabalhos, sendo apenas quatro as pesquisas documentais e bibliográficas, estas aqui entendidas

4. Adotaremos no artigo o termo no feminino, para limitar o sexismo na linguagem e porque as professoras representam a maioria do contingente de docentes nos anos iniciais. 
conforme a classificação de Marconi e Lakatos (2003), ou seja, a pesquisa com base em documentos, sejam eles primários ou secundários.

Os nove trabalhos de base empírica incluíram análises de práticas pedagógicas de trinta e duas professoras, sendo que oito destes trabalhos empregaram a observação como procedimento de coleta de dados e um realizou grupos focais com professoras. Por vezes, tais procedimentos eram associados e incluíram ainda identificação do desempenho de estudantes, análise de propostas pedagógicas e notas de campo.

O primeiro grupo é composto por sete artigos sobre pesquisas empíricas envolvendo práticas pedagógicas que consideram importante o desenvolvimento da consciência fonológica nas práticas de professoras alfabetizadoras, e em todos eles houve a indicação de que as professoras recorreram à consciência fonológica.

Bazzo e Godoy (2012) apontam práticas pedagógicas de alfabetização realizadas em um projeto de extensão. $\mathrm{O}$ artigo enfatiza a importância da consciência fonológica quando a descreve como sendo um processo de: "decodificação [...] essencial e fundante das habilidades de leitura [e que] se desenvolve sobre uma habilidade que tem sido apontada como diretamente relacionada à aprendizagem alfabética" (BAZZO; GODOY, 2012, p. 387). Nas ações analisadas realizaram-se várias práticas que incluíram o desenvolvimento da consciência fonológica, como jogos, dramatização, contos e crônicas, parlendas, trava-línguas, músicas e cantigas de roda. Em relação às parlendas e trava-línguas, as autoras apontam que estimulam a memória e produção ou repetição de sequências fonológicas, e que a musicalidade de suas rimas auxiliou na alfabetização e no desenvolvimento da leitura. $O$ trabalho mostrou que é possível trabalhar com vários gêneros do discurso, de variadas formas, com atividades diferentes e potencializar o processo de alfabetização e a consciência fonológica em particular. As autoras trazem no início do artigo a concepção de alfabetização que adotam: “[...] linguagem como enunciativo-discursiva, ou seja, o discurso concebido como prática social e forma de interação" (BAZZO; GODOY, 2012, p. 383), e defendem que a partir desta base se pode trabalhar unidades menores da língua.

Albuquerque, Morais e Ferreira (2008) investigaram a prática pedagógica de professoras alfabetizadoras, para as quais não há contradição em alfabetizar a partir de textos e também explorar a consciência fonológica (ALBUQUERQUE et al., 2008, p. 256). O artigo analisa práticas pedagógicas de três professoras. A primeira delas estava preocupada com a aquisição do sistema de escrita alfabética (SEA), fazendo a "contagem de letras de palavras, partição escrita de palavras em letras, partição escrita de palavras em sílabas e comparação de palavras quanto à presença de sílabas iguais/ 
diferentes" (ALBUQUERQUE et al., 2008, p. 257). A segunda professora alfabetizava a partir de um método "tradicional com uma nova roupagem" (ALBUQUERQUE et al., 2008, p. 259), partindo de textos para ensinar as unidades menores da língua, fazendo adaptações próprias em seu cotidiano de sala de aula a partir das orientações sobre o letramento no processo de alfabetização. Já a terceira professora priorizava a leitura de textos e não estava tão preocupada com o ensino sistemático do SEA (ALBUQUERQUE et al., 2008, p. 261). O artigo aponta que esta professora não conseguiu alfabetizar os seus alunos, pois estava realizando um trabalho pedagógico que focava apenas no letramento, sem o ensino do sistema alfabético, deixando de lado a alfabetização, e a própria professora percebeu essa limitação, ao afirmar que sabia por que seus alunos não estavam alfabetizados: "eu trabalho muito com leitura e produção de textos, mando desenhar, mas não realizo essas atividades de reflexão com as palavras. Agora vou fazer diferente" (ALBUQUERQUE et al., 2008, p. 262). Embora o artigo não explicite em nenhuma prática das professoras o termo "consciência fonológica", é possível notar sua presença em algumas práticas, quando, por exemplo, as professoras 1 e 2, ao ensinar o SEA, utilizam recursos como rimas e aliterações, bem como separações em sílabas, que levam o aluno a refletir sobre a sonoridade das palavras. Entendemos, com as autoras, que as duas primeiras professoras utilizaram em suas práticas de alfabetização mecanismos referentes à consciência fonológica e fonêmica, possibilitando que as crianças caminhassem rumo à alfabetização.

O artigo de Souza e Cardoso (2012) analisa a prática pedagógica de uma professora que incluiu o desenvolvimento da consciência fonológica na alfabetização buscando "que a criança compreenda o processo de codificação e decodificação, mas com compreensão" (SOUZA; CARDOSO, 2012, p. 6). Quanto à consciência fonológica, foi possível encontrar mais explicitamente, em determinado trecho da entrevista, a indicação de suas práticas: "Primeiro a gente vai cantar a música, em seguida [...] vai ler o texto [...] escrito num cartaz ou no quadro. [...] Faz a leitura, pedacinho por pedacinho fazendo as boquinhas juntos" (SOUZA; CARDOSO, 2012, p. 7). Fica evidente a presença da consciência fonológica no processo de alfabetização. Ela valoriza tanto as unidades maiores do texto quanto as menores, pois entende que sem o domínio destas últimas não é possível que se leia um texto.

Cruz e Albuquerque (2012) apontam que as professoras investigadas acreditavam que era preciso promover a aquisição da escrita no primeiro ano, e nos dois seguintes focar na consolidação da leitura e na produção textual, com textos de diferentes gêneros. Embora as professoras buscassem alfabetizar letrando, nota-se 
que no primeiro ano não julgavam importante que as crianças produzissem textos, dissociando a prática de produção textual da aquisição da escrita alfabética, distanciando estes dois processos, e caminhando na direção contrária da indicada por Fayol e por Soares, desvinculando, portanto, as facetas linguística e interativa. A ênfase era na apropriação da escrita alfabética, "com base em atividades como: exploração das letras do alfabeto, reflexão entre as unidades sonoras das palavras e suas correspondentes na escrita" (CRUZ; ALBUQUERQUE, 2012, p. 7).

Em Oliveira (2006) temos também a indicação de que as professoras estavam preocupadas em utilizar os textos em suas aulas, e no primeiro ano igualmente prevalecia a preocupação com o sistema de notação alfabética, inclusive com a reflexão fonológica; somente nos anos seguintes é que a preocupação com os textos predominava. As professoras dos primeiros anos pareciam estar mais preocupadas com a construção do sistema de notação alfabética pelo aprendiz do que com a produção textual. Embora utilizassem o texto, tinham a finalidade de "explorar os sons da escrita" e os "padrões silábicos" (OLIVEIRA, 2006, p. 7). Do mesmo modo que no artigo de Cruz e Albuquerque, a indicação é da não articulação entre a apropriação da escrita (faceta linguística) e a produção textual (parte integrante da faceta interativa).

O artigo de Macedo, Almeida e Tibúrcio (2017) apresenta o resultado de duas pesquisas que investigaram a prática de duas professoras quanto às concepções, práticas e recursos didáticos voltados para o ensino da leitura e da escrita. Ambas trabalhavam com a consciência fonológica em suas práticas pedagógicas de alfabetização, porém, com prioridades diferentes. No que tange à primeira pesquisa, para ensinar a ler e escrever o ponto de partida da professora se centrava no ensino das letras do alfabeto. "No alfabeto, viam-se as quatro formas da letra (maiúscula, minúscula, cursiva e impressa), uma figura e uma palavra”. (MACEDO et al., 2017, p. 222). Podemos observar na prática dessa professora a preocupação com o ensino do SEA, porém com práticas descontextualizadas e sem buscar a atribuição de sentidos pelas crianças na leitura. Segundo as pesquisadoras, essa professora utilizava recursos como "cruzadinhas; caça-palavras; formação de palavras a partir de sílabas; completar palavras com letras ou sílabas faltosas, recorte e colagem de letras e palavras; ditados; separação de palavras em sílabas; cópia e leitura de textos acartilhados” (p. 224). A produção textual estava ausente das práticas observadas, que, quanto à escrita, voltavam-se para as cópias. Fica clara a opção metodológica de privilegiar os métodos sintéticos, com base na crença de que a aprendizagem requer memorização, escolha criticada pelas autoras, por considerarem que em tal prática "a escrita é vista como um código de transcrição 
das unidades sonoras em unidades gráficas" (MACEDO et al., 2017, p. 227). Quanto à prática da professora na segunda pesquisa, ela partia de um trabalho com textos e contextos significativos para as crianças na alfabetização (MACEDO et al., 2017, p. 228). Conforme as autoras, para a professora, reconhecer fonemas era fundamental para o aprendizado da leitura e escrita, como podemos notar a seguir: "para aprender a ler e escrever, a gente tem que começar assim, olha: fazendo o barulhinho das letras" (MACEDO et al., 2017, p. 231). Desse modo, diferentemente da professora anterior, esta também trabalhou com questões de aquisição do SEA e da consciência fonológica, porém em situações de aprendizagens significativas e contextualizadas, e articulando as facetas envolvidas.

Notamos no artigo de Melo e Magalhães (2013), o último deste grupo, que na prática da professora estudada houve muita ênfase na leitura, na interpretação e na oralidade, e pouca na aquisição do SEA, analisado como tendo sido "episódico e casual", já que "apenas por uma vez ela desenvolveu na atividade de escrita e reescrita de frases reflexões ligadas ao sistema de escrita” (MELO; MAGALHÃES, 2013, p. 11). As autoras apontam que a professora reportava à aprendizagem do SEA, inclusive com práticas de desenvolvimento da consciência fonológica, ainda que não com essa nomenclatura. Porém, como ressaltam as autoras, eram poucos esses momentos, que precisariam ser ampliados, para que as crianças caminhassem rumo à aquisição do sistema de escrita alfabética.

No segundo grupo de artigos, como já indicado, foram reunidas quatro pesquisas de cunho documental e bibliográfico, que examinaram documentos ou realizaram investigação bibliográfica e foram incluídos neste estudo pela sua potencialidade de impactarem as práticas pedagógicas.

O artigo de Cunha e Santos (2012) empreende uma análise dos estudos sobre dificuldades de aprendizagem de leitura e escrita. Embora sem destacar a consciência fonológica, as autoras incluem este elemento dentre os que influenciam o desempenho na leitura, além da memória, acesso e precisão de acesso léxico e do processamento cognitivo geral (p. 838).

Cornélio, Rodrigues e Becalli (2012) analisam dois documentos, MEC/UNESCO (2003) e Brasil (2007), este último uma publicação da Comissão de Educação e Cultura do Congresso Nacional. O documento da Unesco não aborda a faceta linguística, pelo que se depreende da análise das autoras. Já o brasileiro faz menção a aspectos específicos desta faceta e em particular à consciência fonológica. Adotando a perspectiva de Soares $(1985 ; 2004)$, da necessidade de reinventar a alfabetização e 
recuperar sua especificidade, as autoras apontam que o documento defende os aspectos fonológicos na alfabetização, mas nega os aspectos sociais, culturais e políticos, fruto das contribuições de Paulo Freire para conceber a alfabetização. Temos então a defesa das autoras das especificidades das facetas linguística e sociocultural.

Encontramos no artigo de Sousa, Nogueira e Melim (2015) o estudo de dois programas de formação de professores alfabetizadores, o Além das Palavras, que adotou os materiais do Instituto Alfa e Beto, de base fônica, e o Pacto Nacional de Alfabetização na Idade Certa - PNAIC, cujos pressupostos teóricos buscam a articulação entre alfabetização e letramento, os mesmos das autoras do trabalho. No primeiro programa, a adoção de um método fônico já pressupõe trabalho pedagógico intensivo com a consciência fonológica, e segundo um dos estudos que o embasam (OLIVEIRA, 2004), reabilitando os proscritos: memorização, caligrafia, ditado e cópia. Quanto ao PNAIC, sobre a consciência fonológica, as autoras a conceituam (SOUSA et al., 2015, p. 11) e apontam que, para desenvolvê-la, "o professor conta com um rico repertório de parlendas, cantigas, quadrinhas, trava-línguas, poemas e outros textos [...] geralmente bem conhecidos e repetidos em brincadeiras e jogos infantis [...]" (Idem, p. 11). Assim, na perspectiva das autoras, as propostas do PNAIC conseguem articular as diferentes facetas envolvidas no processo de aquisição da língua escrita, enquanto as propostas do Instituto Alfa e Beta secundarizam as facetas que compõem o letramento.

Por último, Trindade, Mello e Silva (2015) analisam o Programa Nacional do Livro Didático - PNLD e a Provinha Brasil, contrapondo-os a materiais voltados para a alfabetização. Na Provinha Brasil se encontra como descritores chave "reconhecer letras e sílabas, a relação grafema-fonema e ler palavras com sílabas canônicas (consoante/vogal) e não canônicas (vogal/consoante/vogal)" (TRINDADE et al., 2015, p. 848). Segundo as autoras, a prova dá maior destaque à alfabetização, o que para elas indica a separação entre a alfabetização e o letramento. $O$ trabalho indica ainda que o PNLD parece ter dado novo vigor aos estudos sobre consciência fonológica, associando-a à implantação do ensino de 9 anos.

No terceiro grupo foram incluídos os artigos de pesquisas empíricas que criticam a consciência fonológica, por se considerar importante considerar suas argumentações, assim como para indicar sua presença no campo, que é baixa, com dois artigos de um total de treze. Esse agrupamento contém dois trabalhos que analisaram práticas de professoras alfabetizadoras e recusam a utilização da consciência fonológica em sala de aula. Elas defendem uma alfabetização de concepção enunciativa 
pautada no letramento, como se evidencia no trabalho de Correia (2012), que considera que as práticas das professoras observadas eram puramente mecânicas e não consideravam a língua como objeto vivo, de diálogo. Ao analisar uma cena, a autora afirma que "analisar a cena apresentada é trazer à tona a crítica feita por Bakhtin (1995) à inadequação dos procedimentos de análise linguística como a fonologia, a morfologia e a sintaxe, para o estudo e explicação do funcionamento da linguagem" (CORREIA, 2012, p. 717). A professora em questão recorria apenas às unidades menores da língua, sem valorizar a significação e o sentido para as crianças. Se de fato é limitante uma prática voltada para as unidades da língua, por outro lado não é possível prescindir do trabalho fonológico na alfabetização; como defende Soares (2017, p.36), "uma só faceta de uma pedra lapidada não é a pedra; um só componente - faceta - do processo de aprendizagem da língua escrita não resulta em criança alfabetizada e letrada".

O trabalho de Santos e Jordão (2014) descreve e analisa "a interação em uma sala de aula de alfabetização, a fim de investigar a articulação entre sua materialidade discursiva e seu funcionamento didático" (SANTOS; JORDÃO, 2014, p. 33). Foi realizado um trabalho com alguns gêneros textuais, mas em nenhum momento eram focalizadas as unidades menores da língua. Fica evidenciado que tanto a postura da professora investigada, quanto a dos autores, é de que privilegiaram apenas a faceta da interação, que, entretanto, não se mostrou eficiente ou suficiente.

A baixa prevalência de artigos neste grupo indica, por um lado, que boa parte do campo dos estudos sobre alfabetização, mesmo aqueles que não defendem os métodos de base fônica, reconhece a necessidade de estudos e práticas pedagógicas voltados para esta parte da faceta linguística no processo de aquisição da língua escrita. Por outro lado, preocupam os estudos que desconsideram a necessidade de também olhar para a consciência fonológica na alfabetização.

Quanto ao objetivo de identificar a presença e as formas do trabalho com o desenvolvimento da consciência fonológica em relatos de pesquisas das práticas pedagógicas de professoras alfabetizadoras, uma primeira observação decorrente do estudo é a de que não foi possível encontrar um grande número de pesquisas voltadas para as práticas das professoras alfabetizadoras que discutissem as abordagens teóricas e práticas pedagógicas sobre a consciência fonológica. Muitas vezes foi possível identificar práticas que propiciam o desenvolvimento da consciência fonológica, porém em geral foram pouco explicitadas, parecendo que apenas intuíam o trabalho com esta dimensão. A escassez de pesquisas que trazem à tona a consciência fonológica pode ter relação com a controvérsia e a discussão 
no campo da alfabetização em relação aos métodos e práticas que privilegiam ou mesmo recusam certas facetas.

Um dos dados mais preocupantes é o do grupo de trabalhos que rejeita como necessária para a alfabetização a consciência fonológica, ao defenderem uma alfabetização de concepção enunciativa, pautada no discurso e nas práticas de letramento. Cabe indagar sobre as possíveis relações entre a formação de professoras alfabetizadoras, inicial ou continuada, e a preponderância, limitação ou exclusão de alguma das facetas, como problematizam Albuquerque et al. (2008), que associam a ausência de algumas delas ao fracasso na alfabetização.

Pudemos notar com base nas pesquisas analisadas que quando há o desenvolvimento da consciência fonológica as crianças apresentam maiores chances de alfabetização, que requer a ampliação de práticas contextualizadas. Soares (2017) deixa claro que não podemos encarar o necessário como suficiente, ou seja: a faceta linguística é necessária e importante no processo de alfabetização das crianças, no entanto, são necessárias as outras duas facetas, compondo o letramento, para que ocorram práticas efetivas, pois "não se pode reduzir a aprendizagem inicial da língua escrita a apenas à faceta linguística, considerando-a como condição e pré-requisito para a interação com textos reais e para a produção de textos reais”. (SOARES, 2017, p. 349).

Desse modo, compreendemos que a consciência fonológica, aqui apresentada, é apenas uma das facetas importantes para a alfabetização. A integração entre as várias facetas propicia que a criança domine o sistema representacional e notacional da língua escrita e, além disso, "vá também aprendendo a compreender e interpretar textos" (SOARES, 2017, p. 350). Assim, caminha no aprendizado da língua, conhecendo suas unidades maiores e menores, em contextos reais de usos.

\section{REFERÊNCIAS}

ALBUQUERQUE, Eliana Borges Correia; MORAIS, Artur Gomes; FERREIRA, Andréa Tereza Brito. As práticas cotidianas de alfabetização: o que fazem as professoras? Revista Brasileira de Educação, Rio de Janeiro, v. 13, n. 38, p. 252-265, maio/ago. 2008.

BAKHTIN, Mikhail. Marxismo e filosofia da linguagem. Trad. Michel Lahud; Yara Frateschi Vieira. 5. ed. São Paulo: Hucitec, 1995.

BAZZO, Jilvania Lima Santos; GODOY, Dalva. Linguagens, sons e cores: ou sobre o aprendizado da leitura. Leitura: teoria \& prática, Campinas, ano 30, n. 58, p. 383-391, jun. 2012. Suplemento especial $18^{\circ}$ COLE. Disponível em: <http://alb.org.br/wp-content/uploads/2015/11/ltp_58_ suplemento_18cole.pdf>. Acesso em: 16 jan. 2019. 
BRASIL. Congresso Nacional. Câmara dos Deputados. Comissão de Educação e Cultura. Grupo de trabalho alfabetização infantil. Os novos caminhos: relatório final. 2. ed. Brasília: Câmara dos Deputados, Coordenação de Publicações, 2007.

CORNÉLIO, Shenia D’Arc Venturim; RODRIGUES, Ednalva Gutierrez; BECALLI, Fernanda Zanetti. Alfabetização, ciência e ideologia. Leitura: teoria \& prática, Campinas, ano 30, n. 58, p. 688-695, jun. 2012. Suplemento especial $18^{\circ}$ COLE. Disponível em: <http://alb.org.br/wpcontent/uploads/2015/11/ltp_58_suplemento_18cole.pdf>. Acesso em: 16 jan. 2019.

CORREIA, Joelma Reis. A concepção de linguagem de professoras alfabetizadoras e sua influência no ensino do ato de ler. Leitura: teoria \& prática, Campinas, ano 30, n. 58, p. 706723, jun. 2012. Suplemento especial $18^{\circ}$ COLE. Disponível em: <http://alb.org.br/wp-content/ uploads/2015/11/ltp_58_suplemento_18cole.pdf >. Acesso em: 16 jan. 2019.

CUNHA, Neide Brito; SANTOS, Acácia Aparecida Angeli. Inter-relação entre dificuldades de aprendizagem de leitura e escrita. Leitura: teoria \& prática, Campinas, ano 30, n. 58, p. 837-844, jun. 2012. Suplemento especial $18^{\circ}$ COLE. Disponível em: <http://alb.org.br/wp-content/ uploads/2015/11/ltp_58_suplemento_18cole.pdf>. Acesso em: 16 jan. 2019.

CRUZ, Magna do Carmo Silva; ALBUQUERQUE, Eliana Borges Correia. A relação entre as práticas de alfabetização e as aprendizagens das crianças nos três anos iniciais do ensino fundamental em escolas organizadas em série e em ciclos. In: $35^{\text {a }}$ REUNIÃO NACIONAL DA ANPED, Porto de Galinhas - PE, 2012. Disponível em: <http://www.anped.org.br/sites/default/files/gtı2015_res.pdf $>$. Acesso em: 16 jan. 2019.

FAYOL, Michel. Aquisição da escrita. São Paulo: Parábola Editorial, 2014.

LEAL, L. N. MP fiscaliza com autonomia total. Jornal do Brasil, Rio de Janeiro, p. 3, 25 abr. 1999.

MACEDO, Maria do Socorro Alencar Nunes; ALMEIDA, Ana Caroline; TIBÚRCIO, Ana Paula do Amaral. Práticas de alfabetização com crianças de seis anos no ensino fundamental: diferentes estratégias, diferentes concepções. Cadernos CEDES, Campinas, v. 37, n. 102, p. 219-236, maio/ago. 2017.

MARCONI, Marina Andrade.; LAKATOS, Eva Maria. Fundamentos de metodologia científica. São Paulo: Atlas, 2003.

MEC/UNESCO. Alfabetização como liberdade. Brasília: MEC, 2003.

MELO, Terezinha Toledo Melquíades; MAGALHÃES, Luciane Manera. O desafio do "alfabetizar letrando" em sala de aula: um estudo de caso. In: $36^{\text {a }}$ REUNIÃO NACIONAL DA ANPED. Goiânia - GO, 2013. Disponível em: <http://www.anped.org.br/sites/default/files/gt1o_3426_ resumo.pdf $>$. Acesso em: 16 jan. 2019.

MORTATTI, M. R. L. A “querela dos métodos" de alfabetização no Brasil: contribuições para metodizar o debate. Acolhendo a Alfabetização nos Países de Língua Portuguesa, v. 3, n. 5, p. 91-114, set./fev, 2009. Disponível em: <https://doi.org/10.11606/issn.1980-7686.v3isp91-114>. Acesso em: 18 jan. 2019.

OLIVEIRA, Solange Alves. O sistema de notação alfabética como objeto de ensino e de avaliação num regime ciclado: concepções da prática. In: $29^{a}$ REUNIÃO NACIONAL DA ANPED. Caxambu - MG, 2006. Disponível em: <http://29reuniao.anped.org.br/trabalhos/trabalho/ GT10-2314--Int.pdf>. Acesso em: 16 jan. 2019. 
SANTOS, Sandoval Nonato Gomes; JORDÃO, Heloisa Gonçalves. Interação e trabalho docente em aula de alfabetização. Trabalhos em Linguística Aplicada, Campinas, v. 53, n. 1., p. 33-54, jan./ jun. 2014 .

SCHREIBER, Mariana. Governo Bolsonaro: Contra 'ideologia' na alfabetização, novo secretário quer guinada metodológica no ensino. BBC News Brasil. Brasília, 14 jan. 2019. Disponível em: <https://www.bbc.com/portuguese/brasil-46863916>. Acesso em: 18 jan. 2019.

SEMIS, Laís. "Vivi o Estado Novo e passei pela ditadura, mas nunca vi um período tão assustador como este na Educação”. Nova escola, 10 jan. 2019. Disponível em: <https://novaescola.org. $\mathrm{br} /$ conteudo/15004/vivi-o-estado-novo-e-passei-pela-ditadura-mas-nunca-vi-um-periodo-taoassustador-como-este-na-educacao >. Acesso em: 18 jan. 2019.

. Alfabetização: a questão dos métodos. São Paulo: Contexto, 2017.

. As muitas facetas da alfabetização. Cadernos de Pesquisa, v. 52, p. 19-24, fev. 1985.

SOARES, Magda B. Letramento e alfabetização: as muitas facetas. Revista Brasileira de Educação, Rio de Janeiro, n. 25, p. 1-17, jan./fev./mar. 2004. Disponível em: <http://www.scielo.br/pdf/rbedu/ n25/n25a01.pdf $>$. Acesso em: 28/ jul. 2009.

SOUSA, Sandra Novais; NOGUEIRA, Eliane Greice Davanço; MELIM, Ana Paula Gaspar. Um cenário, duas técnicas: análise dos pressupostos teóricos dos programas alfa e beto e PNAIC. In: $37^{\mathrm{a}}$ REUNIÃO NACIONAL DAANPED. Florianópolis, 2015. Disponível em: <http://37reuniao. anped.org.br/wp-content/uploads/2015/o2/Trabalho-GT10-3694.pdf>. Acesso em: 16 jan. 2019.

SOUZA, Ivânia Pereira Midon; CARDOSO, Cancionila Janzkovski. Práticas de alfabetização e letramento: o fazer pedagógico de uma alfabetizadora bem sucedida. In: $35^{\text {a }}$ REUNIÃO NACIONAL DA ANPED. Porto de Galinhas - PE, 2012. Disponível em: <http://www.anped. org.br/sites/default/files/gt10-1637_int.pdf>. Acesso em: 16 jan. 2019.

TRINDADE, Iole Maria Faviero; MELLO, Darlize Teixeira; SILVA, Thaise. A atualização dos primeiros métodos de alfabetização em propostas contemporâneas. Educação e realidade, Porto Alegre, v. 40, n. 3, p. 829-857, jul./set. 2015.

\section{SOBRe AS AUTORAS}

Amanda dos Reis Hermann é graduada em Pedagogia (Universidade Federal de São Carlos). Atualmente é mestranda em Linguística (Universidade Federal de São Carlos) e professora do Ensino Fundamental. Tem experiência na área de aquisição da língua materna, letramento, dialogicidade, leitura e escrita.

E-mail: hermannar27@gmail.com.

Heloisa Chalmers Sisla é graduada em Pedagogia (Universidade de São Paulo), tem Mestrado em Educação em Museu (Bank Street College of Education) e Doutorado em Educação (Universidade Estadual Paulista Júlio de Mesquita Filho). É professora do Departamento de Teorias e Práticas Pedagógicas da 
Universidade Federal de São Carlos. Tem experiência na área de ensino de leitura e escrita nos anos iniciais do Ensino Fundamental, com pesquisas nos seguintes temas: letramento; ensino de produção textual; ensino de compreensão leitora; formação de professores/as.

E-mail: heloisasisla@gmail.com.

Recebido em 21 de janeiro de 2019 e aprovado em 14 de julho de 2019. 